\title{
Looking in on Music: Challenges and Opportunities for the Scholarship of Teaching and Learning
}

\section{ABSTRACT}

Whereas most articles in this special issue demonstrate careful and close-up views of Scholarship of Teaching and Learning (SoTL) in a performing arts or humanities discipline, my approach is opposite; I look in on music teaching and learning to interrogate current conceptions of SoTL. I begin with Sloboda's cognitive explanation of music expertise and consider how music expertise is established relatively early in life. I then proceed to develop two case studies of music in higher education showing how each case illustrates expertise, and highlighting experts' desires for progressively greater challenges. I argue that collaboration with other expert performers is one sort of challenge that meets such desires. By drawing attention to collaboration, I then reframe music as social practice, and I highlight the qualities of participatory performance. In the latter part of the article, I turn my attention toward explaining what it means to think about learning as participation in a community of practice, and I draw on the case studies to demonstrate that such a view presents both challenges and opportunities for SoTL.

\section{KEYWORDS}

learning as acquisition, learning as participation, liberal education, musical expertise, music industry, presentational performance, participatory performance

\section{MUSIC EXPERTISE}

One approach to the scholarship of teaching and learning relies on cognitive science for models of expertise. Scholars reason that, with a clear model of expertise in a given domain, they can recognize how students are moving along a continuum towards expert-level evaluation, reasoning, and problemsolving, and they can develop instructional strategies that move students closer to expertise. In other words, learning is framed as acquisition of expertise. Although many fields derive characteristics of expertise from a general cognitive model, music scholars benefit from several decades of research on music expertise, and specifically from a model of how expertise develops. According to John Sloboda, opportunities to acquire music expertise occur early in life and frequently outside of formal education. He indicates that one becomes a musical expert due to one's existence in a particular culture with musical "forms that have perceptible structures." By this, Sloboda means that the practices of Western European classical music have different structures than, for example, the practices of Indian classical music. An individual typically becomes expert in the musical culture to which she or he has frequent exposure. There are two types of psychological experiments that substantiate Sloboda's claim. The first type of study tests infant preferences for patterns typical of a musical culture. Krumhansl and Jusczyk, for instance, found that North American infants presented with Mozart minuets in normal and abnormal phrase structures showed preference for the normal structures. ${ }^{2}$ The second type of experiment involves comparing professional musicians to adult non-musicians in their judgment of musical patterning. In a task called priming, a chord or tone is played, and then the subject is asked to judge how well a second 
tone or chord is related to the first. Bigland et al. found no significant differences between the adult professional musicians and the adult non-musicians in their ability to make accurate judgments on the priming task. ${ }^{3}$ Taken together, these types of experiments demonstrate that musical enculturation begins at birth (and perhaps before birth), and music expertise develops through exposure to music rather than through formal study.

Sloboda continues by using the story of the famous jazz cornetist, Louis Armstrong, as a prototype of expertise: Armstrong spent his formative years in Storeyville, an area for prostitution that had dance bands on the street. As a teenager, Armstrong acquired his first cornet and met Joe Oliver, the best cornetist in New Orleans; however, Armstrong did not take formal lessons from Oliver. He merely hung out and listened. At age 19, Armstrong acquired regular work in a riverboat band that played seven nights a week, and by age 23 he was considered a professional musician. Sloboda points out several features of Armstrong's developing expertise: first, he had "casual immersion in a rich, musical environment." Next, his exploration and experimentation occurred "without negative consequences," in this rich environment; consequently, the "distinction[s] between 'practice' and 'performance," were blurred. Armstrong did not learn music from a teacher or by going to school, yet his circumstances created strong "motivation to engage in music." In fact, Sloboda writes that school environments often destroy motivation and are not optimal for development of music expertise. Finally, Sloboda uses Armstrong's example to illustrate that, even after being considered experts, musicians continually seek out greater challenges. ${ }^{4}$

Sloboda's explanations demonstrate that music expertise develops similarly to expertise in other domains through constant exposure and strong motivation for deliberate practice. The individual who becomes expert seeks to expand his or her expertise through progressively greater challenges. However, music expertise differs from some other domains in at least two ways: First, music expertise develops fairly early in life, and second, although there may be a model or mentor involved, the relationship of novice to mentor seldom occurs through formal schooling. What are the implications of this cognitive model for teaching and learning in higher education? In the following section, I develop two case studies of music teaching and learning on college campuses. The first is Balinese gamelan Gita Semara at Gettysburg College. The word gamelan means "to strike," and refers to an ensemble of percussive instruments that are forged by one gamelan maker and traditionally kept together in one village meeting place. Balinese gamelan practices are communal and ceremonial—unlike in the U.S., ceremonies occur nearly every day in Bali-and so the word gamelan has come to refer not only to the collection of instruments, but also to the people who play them. ${ }^{5}$ Gita Semara is like many world music ensembles at liberal arts colleges in the U.S. because it, involves not only music majors, but also students from across the campus. The second case is the Jam Band at the State University of New York (SUNY) Oneonta campus, a combo that plays tunes from a broad cross-section of pop, rock, jazz, $R \& B$, with a focus on improvisation. I use these case studies to illustrate that many undergraduates, not just music majors, arrive on college campuses already musically expert, and I explore ways in which music teaching and learning in higher education represents progressively greater and desirable challenge. ${ }^{6}$

\section{TWO CASE STUDIES OF MUSIC LEARNING IN HIGHER EDUCATION Gamelan Gita Semara}

Gettysburg College is a liberal arts school located near the famous Civil War battle site in Adams County, Pennsylvania. Like many similar institutions, the college prides itself on the academic accomplishments of its students, and their active participation in community service. Amidst typical 
liberal arts offerings, Gettysburg features Civil War Era Studies, the Eisenhower Institute for leadership and public policy, and the Sunderman Conservatory of Music.

Brent Talbot was appointed to Gettysburg College faculty after completing doctoral studies at the Eastman School of Music and being an active participant there in the Balinese gamelan, Lila Muni. Talbot's dissertation used a sociocultural framework to study Balinese music practices as taught in the U.S., and he had made several trips to Bali, to the capital city of Denpasar and also to a smaller village, Banjar Wani to become immersed in Balinese culture. From these experiences, Talbot came to believe that a Balinese gamelan would help Gettysburg students confront Western assumptions about how music is constructed and how music is learned.

Balinese gamelans are tuned differently than Western instruments, and in Balinese tradition, music is learned without the assistance of notation. Instruments reside in a communal space and music is learned by members of the group together-a player cannot take an instrument home to practice as she or he would do in a Western band or orchestra. Talbot capitalizes on these differences, and he uses gamelan Gita Semara as a way to open up critical thinking in music, consistent with the liberal arts tradition. Further, gamelan members volunteer for artistic residencies at Adams County elementary schools, consistent with community service valued at Gettysburg College.

Gita Semara meets on Friday afternoons in a large communal space in Sunderman Conservatory where the instruments are stored. When the weather is pleasant, the gamelan rehearsal moves outside. Participants include music majors and non-music majors, faculty from the conservatory, and staff from the college. The ensemble is neither credited nor graded, yet this is a group that is very committed to music-making. When explaining why they participate, the members of Gita Semara are very consistent. First, even on this small campus, they value membership — belonging — to this specific community. Through rehearsals, residencies in schools, and regional performances, they have gotten to know one another well, in ways that the traditional liberal arts curriculum does not permit. Second, and consistent with a liberal arts tradition, the members view themselves as always seeking new opportunities to challenge their own thinking. Finally, Balinese gamelan is inseparable from its spiritual context, and although none of the participants is Hindu, each of them has high regard for the rituals of gamelan. In spite of the challenges of learning new musical sounds and patterning, the participants find rehearsal meditative and calming on Friday afternoons, especially after a busy week.

Although, in Western fashion, Gita Semara has a set meeting time, in Balinese fashion, the rehearsal begins when everyone arrives. In Balinese pedagogy, the leader plays or sings a part for a specific group of instruments then moves on to the next group while the first group continues playing. Rehearsal moves very quickly, and learning is a process of watching and copying, pitching in when one is able. There is no negative judgment if a player doesn't get his part right away, no calling attention to (socalled) errors. The assumption about learning music is that everyone will catch on through repetition. This is the mode in which Gita Semara works, although there is some accommodation for Western thinking, so rehearsal stops and starts over more than it would in a Balinese context. During my observations, I noticed that the rehearsal stopped only at a participant's request, for instance, when someone wanted to review an instrument part or slow the tempo to rehearse a specific section. Talbot always was aware of which members of the group were struggling and likewise knew which pieces of the repertoire needed more rehearsal, as most Western teachers would know, but his time in Bali, and time in the U.S. with Balinese teachers, taught him to be patient and trust the Balinese process.

One of the greatest challenges for Westerners is learning to negotiate Balinese music as a system of interlocking parts, called kotekan. To the uninformed Western listener, Balinese music sounds like steadily pulsing eighth notes, but this is actually a product of paired instruments-one that plays on the 
main beat and one that plays off the beat. Adding to this effect, the two instruments of a pair are tuned with slight differences, creating a shimmer (which Westerners might consider out of tune). In Balinese tradition, the paired instruments are referred to as male and female, and the music that results is viewed as partnership. The aim of Balinese gamelan is precision in this system of interlocking parts, an aesthetic called sip, meaning tight. This kind of precision is not without parallel in Western music - drum lines are often referred to as "tight," as are jazz ensembles. But in the Balinese context, which is a spiritual context, the meaning of sip transcends precision to signify a sense of unity - the music cannot exist without the partnership of the players who are making it. When I ask Talbot how he knows the participants in Gita Semara are learning, he responds quickly and easily: they no longer demonize aural learning, they find the lack of notation not only challenging but liberating, and they "get it." I ask him to clarify what "get it" means and he responds, "They understand that the music is all of them. Together." Perhaps Talbot's explanation of "getting it" more accurately describes sip, in both its sound and spiritual senses.

\section{Jam Band}

SUNY Oneonta is a four-year public university in the small town of Oneonta, midway between Albany and Binghamton. The university primarily serves undergraduates and has a small number of graduate or post-baccalaureate programs. Beginning as a normal school, the university still prides itself on a strong teacher preparation program, and it offers a typical catalog of arts and sciences degree programs. Within its list of seventy possible majors, one can find several that are vocationally oriented, including Foodservice and Restaurant Administration, Fashion and Textiles, and Music Industry.

Based on many years of professional experience in music business and media, Joseph Pignato teaches courses in music industry at SUNY Oneonta, but he is a drummer and composer by training, and this work clearly shapes his identity as a teacher and scholar. Pignato's compositions are informed by and feature processes of improvisation, and his scholarship also focuses on improvisation as process. When we sit down to talk, Pignato relates the story of some previous work with children and adolescents on a digital composition project. The two fundamental rules for that project were: 1) feel free to create and explore; and 2) capture everything you do. These pillars of practice also signify the unique work of the Jam Band.

The SUNY Oneonta music department sponsors several pop and rock bands, including an R\&B band, a pop repertory ensemble, and a Zappa band. While other bands seek a stable membership from year-to-year, Jam Band is unique in that Pignato favors focusing on members' learning through their experience in Jam Band, then he encourages them to leave in order to deploy that learning in new musical contexts. The Jam Band comprises mainly music industry majors, but it also includes highly trained classical musicians who love pop music, as well as functional rock musicians from other majors on campus. Pignato points out that SUNY Oneonta is a highly diverse campus, but he admits that most of the students who make their way to Jam Band are White, male, suburban guitarists, drummers, and bass players.

Pignato views the tune as the basic unit of analysis, exploration, performance, and recording. He begins each semester with six or seven tunes from a number of genres; for example, in the semester I observed, there were representative tunes from Steely Dan, Lucinda Williams, the Bee Gees, the Rolling Stones, and Cyndi Lauper. Band members listen to recordings of the tunes in great detail, learning how the tunes are put together rhythmically and harmonically, as well as emotionally. Then the task is to replicate the tunes. Although it may seem easy in principle, it is not simple at all in practice. Each member of the band learns the tunes through a filter of his or her unique background and experience. 
That experience naturally leads to attending to some aspects of performance while avoiding others. During the semester I visited, one of the band members had some success as a roots music performer, while another had a lot of experience singing in Broadway and Contemporary Commercial styles. Still a third band member saw himself primarily as a classical musician. Putting all of these unique backgrounds together in a coherent interpretation of a tune is the first challenge faced by the Jam Band. It requires intense listening, and it most often requires a student to foreground group cohesion and therefore (at least provisionally) abandon his or her own virtuosic performance.

The task is all the more daunting because Pignato rarely tells the band how to solve musical problems. He might intervene in small ways, such as having one player perform while others listen, or turning off the lights in the rehearsal room so players are relying on their ears instead of their eyes. After teaching the Jam Band for several years, Pignato has figured out that he should step in more frequently during the early weeks of a semester when the music is falling apart. By the midpoint of the semester, however, the band must be in charge of solving its own problems to reach the goal of a coherent performance. The Jam Band is assisted in their development by the set up at SUNY Oneonta, where each rehearsal room is also a recording studio. Music industry majors use the Jam Band's rehearsals to gain experience with recording and mixing. In the ethos of "explore, but capture," the band members listen to and reflect on the recordings as a means of musical problem-solving.

The next task is to put the six or seven cover tunes together in a continuous set. This involves group decisions about the order of tunes, how much of any tune to perform, and how to make transitions through tempo and key changes. Sometimes this might mean "mashing up" two tunes, other times, it means learning yet more tunes to use as transition material, and when the band starts to become a more cohesive unit, it might mean inserting fully improvised material. It is always Pignato's goal for the members of the band to develop the degree of listening, trust, and cohesion necessary to create fully improvised music. At the end of the semester, the Jam Band performs their set at a local bar, typically in front of many adoring fans.

When asked about how he knows that students are learning, Pignato systematically refers to the two pillars guiding the experience: are the members of the Jam Band exploring, and are they capturing their explorations? If those things are true, Pignato wants to know whether exploration and reflection are challenging, and therefore transforming, an individual band member's musicianship. What is the band member willing to perform, and able to perform, that was not possible when the Jam Band semester began? More importantly, Pignato knows that learning is occurring when, collectively, the band members "get it," which, to him, means that their process of playing coheres-individuals are no longer pursuing their own virtuosic agendas - and the product of their playing is coherent. But then Pignato adds, "Then I want to know where they take it (both process and product) once it coheres. What do they do with the music after Jam Band?" He implies that, as one instructor of many over a band member's lifetime, he is not privy to the whole trajectory of a student's learning. Furthermore, he implies that the creative process is never finished.

\section{FROM EXPERTISE TO SOCIAL PRACTICE}

Analyzing these cases collectively, we can see that music expertise is fundamental to participation in the ensembles. Students in the Balinese ensemble would not be able to engage in critical thinking, comparing Western musical practices with Balinese practices, if they did not already have some expertise. In the Jam Band, Pignato requires the musicians to be "functional rock musicians" so they can analyze the tunes. Still, neither case limits ensemble participation solely to music majors, so both cases confirm that music expertise is not necessarily tied to ambition for a professional career in music. 
Sloboda's model of music expertise suggests that those who develop expertise seek out progressively greater challenges. Talbot designed the Balinese ensemble for the very purpose of immersing students in new cultural patterns of music, which represents one sort of challenge. Pignato intended the ethos of "explore but capture" in the Jam Band to lead towards fully improvised music, which is another kind of challenge. In both cases, Talbot and Pignato designed environments to support students' further musical development by allowing ample time for "exploration without negative consequences," and intentionally blurring the lines between practice and performance.

But there is a third type of challenge present in both cases: the challenge of collaborating with others in expert music-making. Collaboration is the essence of sip, the feeling of precision towards which Gita Semara strives, and also the essence of improvisation-exploring, listening, reflecting, and responding - that characterizes the Jam Band. Examining recent research on music in higher education, we can see that a goal of collaboration is desirable and extends to music majors as well as non-majors. For instance, the Strategic National Arts Alumni Project (SNAAP) administers an annual survey to alumni of arts training programs in the United States. Respondents answer questions about their current and past education, their satisfaction with curricula, and their current employment. According to SNAAP, $92 \%$ of graduates report that learning to work collaboratively is the most valuable and useful facet of their post-secondary arts education. ${ }^{7}$ Similarly, in their investigations of non-music majors' reasons for engagement with music at the post-secondary level, several researchers find that college students appreciate the opportunity to work collaboratively with peers and to socialize with like-minded people. Furthermore, many non-majors report that their college choice is based on opportunities for musical collaboration. ${ }^{8}$

Amplifying this research, others have studied a specific kind of musical experience, the a cappella ensemble, existing on many college campuses and comprising mainly non-music majors. In contrast to other non-major experiences, ensembles were reported to rehearse six to ten hours per week, and to be engaged for multiple public performances each semester. Members of these ensembles acknowledged the considerable time commitment required, but like those who participated in other musical experiences, a cappella members' participation appeared to be motivated primarily by socializing with like-minded individuals, and the research on a cappella ensembles suggested that strong and long-lasting bonds were promoted in these ensembles. ${ }^{9}$ Paparo called these bonds "fraternal," and he noted that they often extended to an alumni network. ${ }^{10}$

By supporting the claim that collaboration is a desirable challenge for already expert musicians, I argue for envisioning music learning in higher education as social practice. I am not the first to make the case. Ethnomusicologist Thomas Turino promotes a similar view when he describes his own musicmaking preferences:

I greatly prefer to play with others. One of the main things I seek through musical performance is a particular feeling of being deeply bound to the people I am playing with. This sense is created when my partners and I feel the rhythm in precisely the same way, are totally in sync, and can fashion the sounds we are making so that they interlock seamlessly together... This experience is akin to what Victor Turner called communitas, a possible collective state achieved through rituals where all personal differences of class, status, age, gender, and other personal distinctions are stripped away, allowing people to temporarily merge through their basic humanity. ${ }^{11}$ 
Turino goes on to distinguish between presentational and participatory performance contexts, where presentational refers to one group performing music while another observes, and participatory refers to interactive social contexts where everyone present has some role in the music-making. He cautions against the common misconception that participatory performance must be simple: "If everyone is to be attracted, a participatory tradition will have a variety of roles that differ in difficulty and degrees of specialization required." ${ }^{2}$ A range of roles in participatory performance not only offers variety, but also the possibility for an expanding set of challenges, coinciding with Sloboda's model of expertise.

Furthermore, Turino cautions that we should not mistake participatory performance as a substitute for the "real thing." It is common in capitalist societies to assume that music, like sports, must be competitive and profit driven. "Who would buy tickets to watch a pick-up softball game or a square dance?" Turino asks. ${ }^{13}$ However, participatory performance exists in such societies, and it is important because it sustains a particular music tradition, it challenges people to improve their musicianship, and it promotes social interaction and friendship.

Given Turino's explanation, we can see how the two cases of music learning in higher education, Gita Semara and the Jam Band, must count as examples of participatory performance. Framing them in such a way, we focus on students' membership in a community of practice. Each community comprises specific relationships with regard to the music it performs and specific technologies or tools (music instruments, music notation) that mediate the practices of the community. In Gita Semara, a student might participate as a gangsa or reong player. The instruments are played differently and offer different sorts of performance challenges, but the community would not function without both kinds of players. A newcomer to Gita Semara might initially feel most comfortable on jegogan because the part moves more slowly in comparison to other instruments, so the jegogan player "can develop a view of what the whole enterprise is about." ${ }^{14}$ Similarly, in the Jam Band, a student might participate as a keyboard player, a singer, a lead guitarist, or a rhythm guitarist, and some students might change their participation between tunes. The keys to the continuation of the community are: a way into the community for newcomers, and access to resources, including the tools, technologies, and discourses that mediate the practice. ${ }^{15}$ Jenkins and Bertozzi are among several researchers who support the notion that participation in an artistic or creative community is essential in the lives of American youth and young adults. They call this engagement in participatory culture, and they reason that youth and young adults value participation in online communities because of

- Low barriers to artistic expression and civic engagement;

- Strong support for creating and sharing;

- Feeling that their contributions matter to the community;

- Feeling some degree of social connection to other members of the community;

- The community itself provides strong incentives for creative expression and active participation. ${ }^{16}$

Jenkins and Bertozzi make a strong argument that, even where an artistic community is less visible, as is the case in web-based communities, participation is still highly valued. Additionally, the researchers offer a helpful checklist by which participation might be encouraged.

To summarize thus far, I began with the concept of expertise and acknowledged the cognitive model of expertise prevalent in music. I argued that, if we accept the model, we must recognize that music expertise develops early in life, and that music expertise in higher education is not limited to music majors. Like other domains, however, music experts seek out progressively greater challenges, one of which is collaboration with others in expert music-making. Then through two case studies, I showed that 
the feeling of being completely in sync with others, tightness, or "sip" was one realization of collaboration, and trust involved in the acts of listening and responding that constitute musical improvisation was another realization. By emphasizing collaboration, however, I turned my attention toward musicians' participation in a community of practice, and I suggested that college students place a high value on participation in creative communities. Throughout this argument, then, I have been moving away from viewing music learning as acquisition of expertise and towards a view of learning as participation. I now turn fully to frame learning as participation, and drawing from the case studies, I describe both challenges and opportunities for SoTL.

\section{LEARNING AS PARTICIPATION}

In 1991, Jean Lave, a social anthropologist, and Etienne Wenger, then known for his work on intelligent tutoring systems, published their research on communities of practice. They coined the term legitimate peripheral participation "to draw attention to the point that learners inevitably participate in communities of practitioners and that the mastery of knowledge and skill requires newcomers to move toward full participation in the sociocultural practices of a community." ${ }^{17}$ They rejected the term situated learning to analyze this process both because of its emphasis on learning as cognition and its implication that practices were narrow and replicable. Lave and Wenger argued:

Participation is always based on situated negotiation and renegotiation of meaning in the world. This implies that understanding and experience are in constant interaction-indeed, are mutually constitutive. The notion of participation thus dissolves dichotomies between cerebral and embodied activity, between contemplation and involvement, between abstraction and experience. ${ }^{18}$

We can see from the two case studies that music learning involves the whole person, and learning is not merely an intellectual matter, but also includes embodied knowing-ways of being with the music. In the gamelan, the simultaneous hammering and damping of the gangsas and the precision of kotekan require physical coordination and concentration at the same time they require a more cerebral understanding of the instruments' maleness and femaleness. In the Jam Band, listening to a recording and analyzing a tune's harmonic progression is as important as finding the groove during rehearsal.

We also can see how newcomers to a community of practice learn from old-timers, and how newcomers are not merely observers but practitioners, alongside the old-timers. The practices in which newcomers participate are essential, but they may be at the periphery, so newcomers can "gradually assemble a general idea of what constitutes the practice of the community." ${ }^{19}$ Assuming that the newcomer has access, she or he can gain greater understanding of the tools that mediate the practice, including the discourse, and she or he can gradually move towards fuller participation.

To conceive of learning as participation, however, it is essential to understand Lave and Wenger's contention that the view of learning as participation is not a conventional one where apprentices "acquire the 'specifics' of practice through 'observation and imitation." ${ }^{20}$ As newcomers move toward full participation, they gain a sense of belonging, a sense of identity as masterful practitioners. "Learning and a sense of identity are inseparable: They are aspects of the same phenomenon." ${ }^{21}$ When newcomers begin to identify as masterful practitioners, the community of practice is put into motion. Although the community of practice maintains continuity with its history 
and traditions, new practices are acquired, and these displace old ways of doing things. Lave and Wenger argue:
Newcomers are caught in a dilemma. On the one hand, they need to engage in the existing practice, which has developed over time: to understand it, to participate in it, and to become full members of the community in which it exists. On the other hand, they have a stake in its development as they begin to establish their own identity in its future. ${ }^{22}$

The moves of newcomers to old-timers and the simultaneous continuity and displacement of practice can be seen in the case of gamelan Gita Semara, although these aspects of practice were not observable during my short visit. Talbot initially designed the ensemble so that students would engage in critical thinking, comparing their Western music expertise with Balinese practices, but gradually, some Western practices have made their way into the ensemble. For example, there now are sound recordings of all the pieces available on a Blackboard site so members can listen and rehearse "in their heads" between group meetings. Often, the group rehearses by slowing the tempo of a piece, and occasionally some notation is used to help members with recall. These are not traditional Balinese practices, and Talbot did not introduce the practices (although they make their way into most Balinese gamelans that reside in higher education institutions in the United States). The practices were introduced as newcomers engaged in critical thinking and compared Balinese practices with Western ones, just as Talbot envisioned. Gradually, members began to identify themselves as masterful practitioners in Gita Semara, and some members even accompanied Talbot on a study abroad to Bali. But as much as the members understood and honored Balinese practice, they sought to lower barriers to participation for the next group of newcomers, ways to make them feel more quickly that their contributions mattered to the group. So, the Western practices of recording and notation became incorporated into Gita Semara.

\section{CHALLENGE AND OPPORTUNITY FOR SOTL}

As the preceding discussion demonstrates, to frame learning as participation we must observe two movements at once: 1) newcomers move towards fuller participation and identities as masterful practitioners, and 2) the practice changes. These images of learning contrast distinctly with framing learning as acquisition, for with acquisition, we imagine knowledge (or expertise) as a commodity. Like gaining weight or wealth, it is possible to calculate the difference between what our students possessed when they entered our classes or colleges, and what the acquired by the end. The frame of learning as acquisition can be powerful because it allows us to imagine knowledge is stable, as well as to imagine there is always more that might be acquired. No doubt, this is the attraction of the novice-expert continuum for SoTL; expertise, as a cognitive psychology concept, is stable and we can imagine a yardstick from novice to expert, by which students move along in measurable increments.

When we frame learning as participation, however, we are interested in embodied understanding in social context. Rather than being concerned with how much knowledge our students have acquired, we are concerned primarily with who they are, in what activities they choose to engage, and how they navigate membership in a community. Anna Sfard observes that, in the literature on learning as participation, the term knowledge is "replaced with the noun 'knowing,' which indicates action.... The permanence of having gives way to the constant flux of doing." ${ }^{23}$ Flux can be applied not only to the actors and their identities, but also to the practice or discourse in which they participate. According to Lave and Wenger, participation changes over time, but it may not change in significant ways during a semester-long course. Furthermore, as participation changes, so does practice. In SoTL that frames 
learning as participation, scholars would need to document changes in students' participation, and changes to the practice or discourse, perhaps for a number of years. Instead of psychological measurement of knowledge acquisition, our scholarship would become ethnographic, following a community of practice perhaps through a degree program and into the world.

More importantly, with our interest who students are, what they choose to do, and therefore in who they are becoming, we demonstrate an interest in the moral ends of teaching and learning. We are unlikely to face colleagues who contend that Turner's communitas or Turino's sense of belonging are not desirable learning outcomes, but rarely has SoTL been framed by such theoretical concepts. Carolin Kreber argues that "SoTL would be greatly enhanced if it listened not only to psychologically-based theories of learning and instructional design, but also to ... ethics, sociology, anthropology, history, and aesthetics." ${ }^{24}$ Scholars ought to be interested in "what our students learn, who they become, and how they choose to engage with the world... [because these] matter fundamentally to the well being of our local communities and wider society." 25 Taking Kreber's words to heart, interest in who our students are and who they are becoming vis-à-vis the communities of practice in which they are engaged requires SoTL to move beyond framing learning as knowledge acquisition and examining "what works" questions. We must instead engage messier questions of in which communities students desire participation, the portals by which they find their way in, and how they make a web of knowing amongst all the communities in which they participate.

Through the cases of Gita Semara and Jam Band, and taking Turner's communitas and Turino's sense of belonging as theoretical points of departure, we can see that music majors and others already have sought out some kind of music learning, and they will continue participation with or without the formality of college courses precisely because participation affords that sense of communitas, of being deeply bound to those with whom they are playing. Perhaps something similar might be said for the actors, artists, chemists, economists, engineers, historians, mathematicians, philosophers, sociologists, and writers who enter higher education. None enters our college classrooms without desire to continue participation. What can we learn from musicians' participation about teachers' obligations to model intellectually honest discourse, provide authentic tools and technologies, and lay the groundwork for disciplinary communities of practice? Surely, the sense of being deeply bound to others is not generated uniquely from musical participation.

A reader might wonder how learning can be framed as participation in scientific fields with objectivist epistemologies. Even in their discussion of objectivist epistemology, astrophysicists (for example) construct a community of practice. Their discourse includes mapping galaxies, knowing how laws of physics work at the extremes of space and time, and the importance of the quest for understanding dark matter. They have tools and technologies that mediate practice, such as ever more powerful telescopes. Students of astrophysics who have access to tools, technologies and discourse may sense similar deep bonds within their community of practice as musicians feel in theirs. But caution is in order relative to communities of practice in institutions of higher education. Lave and Wenger argue that schools, at any level, are "predicated on claims that knowledge can be decontextualized." ${ }^{26}$ While it is fair to argue that any college class can be a community of practice and to say that students are moving towards fuller participation in that community, scholars must always question what practice is being reproduced in a given classroom. It is conceivable that students are participating merely in the reproduction of schooling, and it seems doubtful that the practices of sitting in rows, memorizing, testtaking, and so forth generate the same kind of ethical encounter with others as is found from participating in a musical community of practice. 
But if framing learning as participation highlights the possibility of communitas, and in turn, if the possibility of communitas directs our attention toward the teacher's obligation to equip students with authentic tools, technologies, and discourse of a discipline, then the teacher's vision and design for learning are paramount in higher education. Here again, we can draw on the two case studies to learn about vision and design. Talbot envisioned his students as musically capable, so he designed Gita Semara to lead students toward juxtaposing Balinese practices with more familiar Western practices. He envisioned students thinking critically about how music is structured and how music is learned, and furthermore, he believed from the outset that they would connect their experiences in Gita Semara to other curricular and co-curricular activities. Gettysburg College's website advertises the importance of experiential learning, small class sizes, and co-curricular activity. It says, in part,

At Gettysburg you learn to think about ideas, problems, solutions, the way things are, and the way things should be .... You graduate with in-depth understanding of your major field(s), with a breadth of knowledge that helps you connect different fields of study, and with practical skills to put your learning into action. ${ }^{27}$

Gita Semara at Gettysburg College was not some happy accident. Talbot's design for the gamelan was intentionally aligned with the broader purposes of liberal education and the ways of being a liberally educated person in the world.

Pignato's design decisions for Jam Band involve choosing tunes, providing the initial recordings, and explaining the "ground rules" for exploring and capturing. These decisions stem from Pignato's years of experience in the music industry and his identity as a drummer and composer. Although he designed Jam Band to begin with members' replication of recordings, Pignato envisioned that Jam Band collaborations would lead toward the kinds of exploration, listening, and responding that characterized improvisation, and improvisation, in turn, would lead towards creating new music. Pignato's vision for the Jam Band is vocationally oriented, tightly coupled to goals of the Music Industry degree program at SUNY Oneonta. Still, it is important to note that vocational aims were not conceived narrowly-Jam Band was not designed to provide a set of skills for employment in the music industry. Instead, Jam Band was designed to facilitate ways of being collaborative and creative-ways of being necessary for participation in professional communities of music production, promotion, and publishing.

In the years when SoTL was just gaining traction, Pat Hutchings and Lee Shulman wrote that an essential attribute of SoTL was "inquiry and investigation, particularly around issues of student learning." 28 To position SoTL as inquiry into student learning is different than using SoTL to improve student learning, which is the purpose so often described today. Improvement of student learning takes a deficit view of students who, as we have established, do not enter higher education as rank beginners, but instead enter with knowledge, know-how, and desire for continued participation. Inquiry instead invites "wide awakeness" - putting learners at the center of the educational enterprise and asking what teaching, within and across disciplines, might contribute towards their life projects. ${ }^{29}$ Through inquiry, I have shown how two cases of music learning might be framed as participation in a community of practice, and I have suggested that communitas is a good that arises from participation. Further, I have suggested that all learning in higher education might be framed similarly. But if learning is participation, then the teacher has an obligation to ensure access to the tools, technologies and discourse that mediate participation in the community of practice. The teacher's role as a designer of the learning space, therefore, is paramount. To the extent that the teacher aligns the design of learning with broader 
purposes of education, she or he not only ensures students' well-being in the classroom, but also the students' well-being in the world.

Susan Wharton Conkling is Professor of Music, Music Education at Boston University, where she teaches graduate and undergraduate courses in conducting, music education methods, and curriculum.

\section{ENDNOTES}

1. John Sloboda, "Musical Expertise," In Toward a General Theory of Expertise: Prospects and Limits, ed. K. Anders Ericsson and Jacqui Smith (Cambridge University Press, 1991), 168.

2. Carol L. Krumhansl and Peter W. Jusczyk, "Infants' Perception of Phrase Structure in Music," Psychological Science 1, no. 1 (1990): 70-73.

3. Emmanuel Bigand, Bénédicte Poulin, Barbara Tillmann, François Madurell, and Daniel A. D'Adamo, "Sensory Versus Cognitive Components in Harmonic Priming," Journal of Experimental Psychology: Human Perception and Performance 29, no. 1 (2003): 159.

4. Sloboda, "Musical Expertise," 161-162.

5. For more details on Balinese gamelan, see Lisa Gold, Music in Bali: Experiencing Music, Expressing Culture (Oxford University Press, 2005).

6. Appropriate protocols concerning the ethical treatment of human subjects were followed for the case studies.

7. Strategic National Arts Alumni Project, Forks in the Road: The Many Paths of Arts Alumni-Annual Report 2011 (Bloomington, IN: Indiana Center for Postsecondary Research, 2011).

8. See Dan Isbell and Ann Marie Stanley, "Keeping Instruments Out of the Attic: The Concert Band Experiences of the Non-music Major." Music Education Research International 5 (2011): 22-32; Dimitra Kokotsaki and Susan Hallam, "Higher Education Music Students' Perceptions of the Benefits of Participative Music Making." Music Education Research 9, no. 1 (2007): 93-109.; and Roger Allan Mantie, "Structure and Agency in University-level Recreational Music Making." Music Education Research 15, no.1 (2013): 39-58.

9. See Joshua S. Duchan, "Powerful Voices: Performance and Interaction in Contemporary Collegiate, A Cappella" (doctoral dissertation, University of Michigan, 2007); Mantie, "Structure and Agency" 2013; and Stephen A. Paparo, "The Accafellows: Exploring the Music Making and Culture of a Collegiate A Cappella Ensemble." Music Education Research 15, no. 1 (2013): 19-38. Paparo, "The Accafellows," 29-30. Victor Turner's concept of communitas is contained in The Ritual Process (Chicago: Aldine, 1969). The quotation is from Thomas Turino: Music as Social Life: The Politics of Participation (University of Chicago Press, 2008), 18.

12. Ibid., 33-34.

13. Ibid., 35.

14. Jean Lave and Etienne Wenger, Situated Learning: Legitimate Peripheral Participation (Cambridge University Press, 1991), 92.

15. Lave and Wenger, Situated Learning.

16. Henry Jenkins and Vanessa Bertozzi, "Artistic Expression in the Age of Participatory Culture: How and Why Young People Create" in Engaging Art: The Next Great Transformation of America's Cultural Life, ed. Stephen J. Tepper and Bill Ivey (New York, Routledge, 2008), 174.

17. Lave and Wenger, Situated Learning, 29.

18. Ibid., 51.

19. Ibid., 94.

20. Ibid., 95.

21. Ibid., 115

22. Ibid., 114

23. Anna Sfard, "On Two Metaphors for Learning and the Danger of Choosing Just One," Educational Researcher 20 no. 2 (1998): 6.

24. Ibid., 12. 
Ibid., 13.

Lave and Wenger, Situated Learning, 39.

Gettysburg College, "After Gettysburg" http://www.gettysburg.edu/about/after_gettysburg.dot

Pat Hutchings and Lee S. Shulman, "The Scholarship of Teaching: New Elaborations, New Developments," Change: The Magazine of Higher Learning 31 no. 5 (1999): 13.

Here I draw on Maxine Greene's elaboration on "wide-awakeness" in "Toward Wide-Awakeness: An Argument for the Arts and Humanities in Education," Teacher's College Record 79 no 1 (1977): 119-125.

\section{(c) (1)}

Copyright for the content of articles published in Teaching \& Learning Inquiry resides with the authors, and copyright for the publication layout resides with the journal. These copyright holders have agreed that this article should be available on open access under a Creative Commons Attribution License 4.0 International (https://creativecommons.org/licenses/by/4.0). The only constraint on reproduction and distribution, and the only role for copyright in this domain, should be to give authors control over the integrity of their work and the right to be properly acknowledged and cited, and to cite Teaching \& Learning Inquiry as the original place of publication. Readers are free to share these materials - as long as appropriate credit is given, a link to the license is provided, and any changes are indicated. 